\title{
Second primary cancer after primary peritoneal, epithelial ovarian, and fallopian tubal cancer: a retrospective study
}

\author{
Myong Cheol Lim²,2,3, ${ }^{1}$ Young-Joo Won ${ }^{4,5^{*}}$, Jiwon Lim5, Tahereh Salehi ${ }^{1}$, Chong Woo Yoo ${ }^{2}$ and Robert E. Bristow ${ }^{1}$
}

\begin{abstract}
Background: In this retrospective study, data from patients listed in the Korea Central Cancer Registry during 19932014 were analysed, to investigate the incidence and survival of second primary cancers (SPCs) after a diagnosis of primary peritoneal, epithelial ovarian, and fallopian tubal (POFT) cancer.

Methods: The standardised incidence ratio (SIR) and survival outcomes of patients with SPCs among POFT cancer survivors were analysed.

Results: Among 20,738 POFT cancer survivors, 798 (3.84\%) developed SPCs, at an average interval of 5.50 years. SPC risk in POFT survivors (SIR, 1.29) was higher compared to the general population. The most high-risk type of SPC was leukaemia (3.07) followed by the lung and bronchus (1.80), colon (1.58), rectum and rectosigmoid junction (1.42), thyroid (1.34), and breast (1.26). In women aged < 60 years, cancer of the breast (1.30), ascending colon (2.26), and transverse colon (4.07) as SPCs increased. Up to 10 years after POFT cancer treatment, leukaemia risk increased, especially in those $<60$ years, with serous histology, and with distant stage, which required aggressive chemotherapy. The median overall survival time was 12.8 years and 14.3 years in women with POFT cancer and SPCS, respectively. Thyroid and breast cancers were favourable prognostic markers among SPCs.

Conclusions: The overall SPC risk increases in POFT cancer survivors, especially in those $<60$ years. The cancer risk of breast and the proximal colon increase based on hereditary predisposition, while leukaemia likely develops from aggressive treatment. The median overall survival is favourable in POFT cancer survivors with SPCs.
\end{abstract}

Keywords: Second primary, Ovarian cancer, Primary peritoneal cancer, Fallopian tubal cancer

\section{Background}

Ovarian cancer is one of the most important gynaecologic cancers. In 2017, there were an estimated 22,440 new cases and 14,080 ovarian cancer deaths in the US [1]. The incidence of ovarian cancer has been continuously increasing, resulting in an annual percent change of $+1.5 \%$ during 1999-2010, with an estimated incidence of 2618 and mortality of 1168 in 2017 in Korea [2, 3]. The high rate of mortality has not improved in the last decade, and survivors of ovarian cancer may further develop a second

\footnotetext{
* Correspondence: astra67@ncc.re.kr

${ }^{4}$ Department of Cancer Control \& Population Health, Graduate School of Cancer Science and Policy, National Cancer Center, Goyang, Republic of Korea

${ }^{5}$ Cancer Registration and Statistics Branch, National Cancer Control Institute,

National Cancer Center, Goyang, Republic of Korea

Full list of author information is available at the end of the article
}

primary cancer (SPC) based on the shared aetiology and treatment sequelae.

Ovarian cancer, diagnosed as C56 by the International Statistical Classification of Diseases and Related Health Problems (ICD), includes epithelial cancer and germ cell cancer among others, and is not a single disease entity in terms of the aetiology, treatment strategies, and prognosis. Basically, epithelial ovarian cancer is the same disease entity as primary peritoneal cancer (C48.2) and fallopian tubal cancer (C57). Accordingly, primary peritoneal, epithelial ovarian, and fallopian tubal (POFT) cancers are diagnosed and treated in similar ways.

POFT cancers have shared genetic backgrounds as parts of hereditary cancers related to $B R C A 1$ and BRCA2 mutations and Lynch syndrome [4]. Moreover, adjuvant chemotherapy after cytoreductive surgery may

(c) The Author(s). 2018 Open Access This article is distributed under the terms of the Creative Commons Attribution 4.0 International License (http://creativecommons.org/licenses/by/4.0/), which permits unrestricted use, distribution, and reproduction in any medium, provided you give appropriate credit to the original author(s) and the source, provide a link to the Creative Commons license, and indicate if changes were made. The Creative Commons Public Domain Dedication waiver (http://creativecommons.org/publicdomain/zero/1.0/) applies to the data made available in this article, unless otherwise stated. 
be associated with chemotherapy-related SPCs. Therefore, the objective of this study was to investigate the patterns and treatment outcomes according to the development and type of SPC after POFT cancers.

\section{Methods}

Analysis of data from the Korea Central Cancer Registry from 1993 to 2014 identified 20,738 patients with POFT cancers. The methodology for this study on SPC after POFT, in terms of the statistical analysis and expression of the results, is the same as in our previous study on SPC after cervical cancer [5]. The methods are described below to help the readers understand this study.

In brief, the standardised incidence ratios (SIRs) and corresponding 95\% confidence intervals (CIs) of SPC among POFT survivors were analysed to quantify the relative risk compared to women in the general population. These SIRs were calculated by dividing the observed number of SPCs by the expected SPC number if the patients in the cohort demonstrated cancer rates equivalent to those for individuals in the general population.

The number of person-years at risk (PYRs) was defined from 2 months after the date of the POFT diagnosis to the date of death or the end date of this study, whichever occurred first. For each initial cancer site grouping, the PYRs and observed cases of cancer were stratified according to 5-year age groups and calendar year. The cancer incidence rates were computed for each subsite of cancer and according to age and calendar year and were multiplied by the accumulated PYRs to estimate the expected number of subsequent cancers for each stratum.

Kaplan-Meier survival curves were calculated for POFT patients with or without an SPC. The differences between the groups were assessed using the log-rank test. All statistical tests were two-sided, and the significance was set at an alpha level of 0.05. To compute the SIRs and their 95\% CIs, we used the "MP-SIR" setting of SEER*Stat 8.3.4. Survival curves were generated and log rank-tests were performed using Stata 11 software (StataCorp. 2009, College Station, TX).

\section{Results}

A total of 20,738 survivors who were diagnosed with POFT cancer were evaluated for a mean follow-up period of $5.68 \pm 5.33$ years (Table 1 ). The mean age at the initial diagnosis of POFT was 51.18 years. The incidence of POFT diagnosis peaked during the ages 50-59 years (28.38\%). Of the 20,738 POFT survivors, 798 (3.84\%) survivors developed an SPC. The mean interval from the initial POFT diagnosis to the SPC was 5.5 years $( \pm 4.71)$, and the mean age at diagnosis with the SPC was 56.00 years $( \pm 11.88)$.

As shown in Table 2, the overall SIR for an SPC was 1.29 (95\% CI, 1.21-1.38). The most high-risk type of
Table 1 Characteristics of patients with primary POFT cancer

\begin{tabular}{|c|c|c|}
\hline Variable & Number & Percent \\
\hline Women with POFT cancer & 20,738 & 100.00 \\
\hline Peritoneal cancer & 506 & 2.44 \\
\hline Epithelial ovarian cancer & 19,767 & 95.32 \\
\hline Fallopian tubal cancer & 465 & 2.24 \\
\hline Average follow-up, years (mean, SD) & 5.68 & 5.33 \\
\hline $\begin{array}{l}\text { Average age at diagnosis of POFT } \\
\text { cancer, years (mean, SD) }\end{array}$ & 51.18 & 13.37 \\
\hline \multicolumn{3}{|l|}{$\begin{array}{l}\text { Age at diagnosis of the 1st primary } \\
\text { cancer, years }\end{array}$} \\
\hline$<30$ & 1346 & 6.49 \\
\hline $30-39$ & 2394 & 11.54 \\
\hline $40-49$ & 5520 & 26.62 \\
\hline $50-59$ & 5885 & 28.38 \\
\hline $60-69$ & 3763 & 18.15 \\
\hline 70-79 & 1597 & 7.70 \\
\hline$\geq 80$ & 233 & 1.12 \\
\hline \multicolumn{3}{|l|}{ Histology } \\
\hline Serous & 11,793 & 56.87 \\
\hline Mucinous & 4332 & 20.89 \\
\hline Endometrioid & 2304 & 11.11 \\
\hline Clear cell & 1929 & 9.30 \\
\hline Others & 380 & 1.84 \\
\hline \multicolumn{3}{|l|}{ Stage ${ }^{*}$} \\
\hline Localized & 3378 & 28.70 \\
\hline Regional & 2365 & 20.09 \\
\hline Distant & 5416 & 46.01 \\
\hline Unknown & 612 & 5.20 \\
\hline Women who developed SPC & 798 & 3.84 \\
\hline $\begin{array}{l}\text { Average interval between first } \\
\text { POFT cancer and SPC, years } \\
\text { (mean, SD) }\end{array}$ & 5.50 & 4.71 \\
\hline $\begin{array}{l}\text { Average age at diagnosis of SPC, } \\
\text { years (mean, SD) }\end{array}$ & 56.00 & 11.88 \\
\hline
\end{tabular}

"Stage data was used since 2006

POFT: peritoneal, epithelial ovarian, and fallopian tubal; SPC: second primary cancer; SD, standard deviation

SPC was leukaemia (3.07), followed by cancer of the lungs and bronchus (1.8), colon (1.58), rectum and rectosigmoid junction (1.42), thyroid (1.34), and breasts (1.26). The SIR of an SPC was higher in young (age $<60$ years) women (1.47; 95\% CI, 1.36-1.59). In these young survivors, the types of highest SPC risk were leukaemia (3.86), cancer of the lungs and bronchus (2.61), colon (2.00), rectum and sigmoid junction (1.67), thyroid (1.35), and breasts (1.30). Of the cases of colon cancer in young women, high observed-to-expected ratios were observed in transverse colon (4.07) and ascending colon cancers (2.26). 
Table 2 Risk of second primary cancer after primary POFT cancer diagnosis by age and follow-up period

\begin{tabular}{|c|c|c|c|c|c|c|c|c|}
\hline & \multicolumn{3}{|l|}{ Total } & \multicolumn{2}{|c|}{ Age (years) } & \multicolumn{3}{|c|}{ Follow-up (months) } \\
\hline & & & & \multirow{2}{*}{$\begin{array}{l}<60 \\
\text { SIR }\end{array}$} & \multirow{2}{*}{$\begin{array}{l}\geq 60 \\
\text { SIR }\end{array}$} & \multirow{2}{*}{$\begin{array}{l}2-59 \\
\text { SIR }\end{array}$} & \multirow{2}{*}{$\begin{array}{l}\text { 60-119 } \\
\text { SIR }\end{array}$} & \multirow{2}{*}{$\begin{array}{l}\geq 120 \\
\text { SIR }\end{array}$} \\
\hline & SIR & O/E & $\mathrm{Cl}$ & & & & & \\
\hline Leukaemia & $3.07^{\#}$ & $(22 / 7.16)$ & $(1.92-4.65)$ & $3.86^{\#}$ & 1.60 & $3.16^{\#}$ & $3.68^{\#}$ & 2.05 \\
\hline Urinary bladder & 1.99 & $(10 / 5.03)$ & $(0.95-3.66)$ & $2.90^{\#}$ & 1.35 & 2.01 & 2.93 & 0.85 \\
\hline Lung, bronchus & $1.80^{\#}$ & $(81 / 44.89)$ & $(1.43-2.24)$ & $2.61^{\#}$ & 1.01 & 1.26 & $2.64^{\#}$ & $1.99^{\#}$ \\
\hline Rectum, rectosigmoid junction & $1.42^{\#}$ & $(47 / 33.04)$ & $(1.05-1.89)$ & $1.67^{\#}$ & 1.08 & 1.53 & 1.35 & 1.27 \\
\hline Thyroid & $1.34^{\#}$ & $(206 / 153.16)$ & $(1.17-1.54)$ & $1.35^{\#}$ & 1.32 & $1.57^{\#}$ & 1.21 & 0.95 \\
\hline Colon & $1.58^{\#}$ & $(122 / 77.38)$ & $(1.31-1.88)$ & $2.00^{\#}$ & 1.03 & $1.69^{\#}$ & 1.34 & $1.60^{\#}$ \\
\hline Ascending colon & $1.77^{\#}$ & $(25 / 14.14)$ & $(1.14-2.61)$ & $2.26^{\#}$ & 1.28 & 1.60 & 1.31 & $2.61^{\#}$ \\
\hline Transverse colon & $2.43^{\#}$ & $(14 / 5.77)$ & $(1.33-4.07)$ & $4.07^{\#}$ & 0.71 & 1.79 & 1.93 & $4.22^{\#}$ \\
\hline Descending colon & 1.17 & $(23 / 19.64)$ & $(0.74-1.76)$ & 1.43 & 0.77 & 1.52 & 1.50 & $0.00^{\#}$ \\
\hline Rectum & $1.45^{\#}$ & $(48 / 33.13)$ & $(1.07-1.92)$ & $1.72^{\#}$ & 1.08 & 1.52 & 1.34 & 1.40 \\
\hline Other and unspecified & $2.55^{\#}$ & $(12 / 4.71)$ & $(1.32-4.45)$ & $4.01^{\#}$ & 1.21 & $3.74^{\#}$ & 0.00 & 2.94 \\
\hline Female breast & $1.26^{\#}$ & $(128 / 101.85)$ & $(1.05-1.49)$ & $1.30^{\#}$ & 0.99 & $1.29^{\#}$ & $1.47^{\#}$ & 0.87 \\
\hline Kidney parenchyma & 1.43 & $(12 / 8.37)$ & $(0.74-2.50)$ & 1.49 & 1.34 & 1.64 & 1.78 & 0.54 \\
\hline Renal pelvis, other urinary & 2.38 & $(5 / 2.10)$ & $(0.77-5.56)$ & 2.31 & 2.43 & 3.02 & 0.00 & 3.69 \\
\hline Pancreas & 1.25 & $(20 / 15.94)$ & $(0.77-1.94)$ & 1.72 & 0.89 & 0.91 & $2.55^{\#}$ & 0.51 \\
\hline Non-Hodgkin lymphoma & 0.88 & $(11 / 12.43)$ & $(0.44-1.58)$ & 1.13 & 0.45 & 1.09 & 0.60 & 0.74 \\
\hline Bile ducts, other biliary & 1.43 & $(26 / 18.23)$ & $(0.93-2.09)$ & $2.20^{\#}$ & 0.86 & 1.57 & 1.01 & 1.61 \\
\hline Stomach & 0.89 & $(67 / 75.35)$ & $(0.69-1.13)$ & 1.15 & $0.55^{\#}$ & $0.56^{\#}$ & 1.34 & 1.15 \\
\hline Liver & 0.68 & $(16 / 23.54)$ & $(0.39-1.1)$ & 0.81 & 0.50 & 0.71 & 0.48 & 0.86 \\
\hline Gallbladder & 0.64 & $(6 / 9.43)$ & $(0.23-1.38)$ & 1.21 & 0.19 & 0.64 & 0.39 & 0.92 \\
\hline Small intestine & 1.93 & $(4 / 2.07)$ & (0.53-4.94) & 3.37 & 0.00 & 1.89 & 0.00 & 4.38 \\
\hline All excluding POFT & $1.29^{\#}$ & $(838 / 647.47)$ & $(1.21-1.38)$ & $1.47^{\#}$ & 0.91 & $1.33^{\#}$ & $1.38^{\#}$ & 1.11 \\
\hline
\end{tabular}

POFT: peritoneal, epithelial ovarian, and fallopian tubal; SIR: standardised incidence ratio; O/E: observed/expected; CI: confidence interval

\#significant at $a=0.05$

Up to 10 years after the initial diagnosis of POFT cancer, the risk of SPCs increased (1.33 until 5 years and after then, 1.38 until 10 years). During the first 5 years of follow-up, the SPC type with the highest SIR was leukaemia (3.16), followed by cancer of the colon (1.69), thyroid (1.57), and breast (1.29). The risk of stomach cancer significantly decreased (0.56) during the first 5 years of follow-up. During 6-10 years of follow-up after the diagnosis of POFT cancer, the overall SIR was 1.38 (95\% CI, 1.21-1.57). The cancer types with the highest SIR were leukaemia (3.68; 95\% CI, 1.48-7.59), lung and bronchus (2.64), pancreas (2.55), and breast (1.47). After 10 years of follow-up, the observed-to-expected ratio of colon cancer increased again (1.60), owing to the increased risks of transverse colon cancer (4.22) and ascending colon cancer (2.61) (Table 2).

In the serous histologic subgroup (Table 3), the risks of leukaemia (4.77) and breast cancer (1.58) were high, whereas the risk of neither cancer was increased in the other histology subgroups, including mucinous, endometrioid, clear, and transitional cell POFT cancers. When the POFT cancers were divided by stage (Table 4), the risk of leukaemia increased in those with distant stage (4.94), but not localized and regional stages. The risk of leukaemia as an SPC after POFT cancer was higher among patients receiving chemotherapy; however, this relationship did not reach statistical significance (hazard ratio, 2.00; $p=0.17$ ).

The median overall survival time was 12.8 years in all women with POFT cancer. In POFT cancer women with an SPC, the median overall survival time was 14.3 years. The 5-year overall survival rates were $88.8,74.4$, and $44.2 \%$ among patients with localized, regional, and distant stage disease, respectively (Additional file 1: Figure S1). The 5-, 10-, and 20-year overall survival rates after the diagnosis of POFT cancer (Fig. 1) were respectively 63.7, 52.5, and 45\% in POFT survivors; 63.0, 52.2, and $46.2 \%$ in POFT cancer survivors without an SPC; and $79.4,62.3$, and $34.5 \%$ in survivors with an SPC. Figure 1 shows the survival curve of women with SPCs compared to women with POFT cancer but without SPCs. Figure 2 shows the survival outcomes according to the site of SPC after the diagnosis of SPC in women with POFT 
Table 3 Risk of second primary cancer after primary POFT cancer diagnosis according to histology

\begin{tabular}{|c|c|c|c|c|c|c|c|c|c|c|c|c|}
\hline \multirow[t]{2}{*}{ Histology } & \multicolumn{2}{|c|}{ Serous } & \multicolumn{2}{|c|}{ Mucinous } & \multicolumn{2}{|c|}{ Endometrioid } & \multicolumn{2}{|c|}{ Clear cell } & \multicolumn{2}{|c|}{ Transitional cell } & \multicolumn{2}{|c|}{ Carcinosarcoma } \\
\hline & SIR & $\mathrm{Cl}$ & SIR & $\mathrm{Cl}$ & SIR & $\mathrm{Cl}$ & SIR & $\mathrm{Cl}$ & SIR & $\mathrm{Cl}$ & SIR & $\mathrm{Cl}$ \\
\hline Leukaemia & $4.77^{\#}$ & $(2.83-7.54)$ & 1.14 & $(0.14-4.11)$ & 0.00 & $(0.00-3.95)$ & 3.48 & $(0.42-12.58)$ & 0.00 & $(0.00-37.27)$ & 0.00 & $(0.00-127.79)$ \\
\hline Urinary bladder & 1.81 & $(0.59-4.22)$ & 1.68 & $(0.20-6.06)$ & 4.59 & $(0.95-13.43)$ & 0.00 & $(0.00-11.77)$ & 0.00 & $(0.00-51.86)$ & 0.00 & $(0.00-128.39)$ \\
\hline Lung, bronchus & 1.08 & $(0.71-1.58)$ & $3.59^{\#}$ & $(2.52-4.98)$ & 1.54 & $(0.70-2.92)$ & $2.51^{\# \#}$ & $(1.08-4.94)$ & 1.52 & $(0.0-8.47)$ & 0.00 & $(0.00-15.84)$ \\
\hline $\begin{array}{l}\text { Rectum, rectosigmoid } \\
\text { junction }\end{array}$ & $1.54^{\#}$ & $(1.03-2.23)$ & 1.22 & $(0.56-2.32)$ & 1.84 & $(0.79-3.62)$ & 0.39 & $(0.01-2.19)$ & 2.06 & $(0.05-11.5)$ & 0.00 & $(0.00-24.49)$ \\
\hline Thyroid & $1.27^{\#}$ & $(1.03-1.55)$ & 1.26 & $(0.93-1.68)$ & $1.77^{\#}$ & $(1.24-2.45)$ & 1.17 & $(0.70-1.83)$ & $2.86^{\#}$ & $(1.05-6.22)$ & 0.00 & $(0.00-9.17)$ \\
\hline Colon & 1.31 & $(0.99-1.7)$ & $1.82^{\#}$ & $(1.23-2.58)$ & $2.56^{\#}$ & $(1.67-3.75)$ & 0.85 & $(0.28-1.98)$ & 2.62 & $(0.54-7.65)$ & 2.75 & $(0.07-15.33)$ \\
\hline Ascending colon & 1.01 & $(0.44-1.99)$ & $2.93^{\#}$ & $(1.34-5.57)$ & 2.73 & $(0.89-6.37)$ & 1.97 & $(0.24-7.11)$ & 0.00 & $(0.00-17.3)$ & 14.02 & $(0.35-78.11)$ \\
\hline Transverse colon & 0.62 & $(0.08-2.24)$ & $3.97^{\#}$ & $(1.29-9.27)$ & $6.68^{\#}$ & $(2.17-15.59)$ & 4.77 & $(0.58-17.24)$ & 0.00 & $(0.00-42.6)$ & 0.00 & $(0.00-126.37)$ \\
\hline Descending colon & 1.01 & $(0.51-1.81)$ & 1.41 & $(0.52-3.07)$ & 1.94 & $(0.63-4.52)$ & 0.00 & $(0.00-2.32)$ & 3.40 & $(0.09-18.96)$ & 0.00 & $(0.00-42.32)$ \\
\hline Rectum & $1.59^{\#}$ & $(1.07-2.29)$ & 1.22 & $(0.56-2.32)$ & 1.83 & $(0.79-3.61)$ & 0.39 & $(0.01-2.18)$ & 2.06 & $(0.05-11.47)$ & 0.00 & $(0.00-24.43)$ \\
\hline Other and unspecified & 2.34 & $(0.86-5.09)$ & 1.78 & $(0.22-6.45)$ & 4.84 & $(1.00-14.14)$ & 0.00 & $(0.00-11.74)$ & 15.06 & $(0.38-83.91)$ & 0.00 & $(0.00-148.5)$ \\
\hline Female breast & $1.58^{\#}$ & $(1.26-1.97)$ & 0.78 & $(0.47-1.22)$ & 1.38 & $(0.83-2.16)$ & 0.48 & $(0.16-1.12)$ & 1.42 & $(0.17-5.14)$ & 3.60 & $(0.09-20.08)$ \\
\hline Kidney parenchyma & 1.75 & $(0.75-3.44)$ & 1.09 & $(0.13-3.95)$ & 0.00 & $(0.00-3.35)$ & 2.85 & $(0.34-10.29)$ & 0.00 & $(0.00-29.83)$ & 0.00 & $(0.00-104.36)$ \\
\hline Renal pelvis, other urinary & 3.37 & $(0.92-8.63)$ & 2.15 & $(0.05-11.98)$ & 0.00 & $(0.00-13.70)$ & 0.00 & $(0.00-27.27)$ & 0.00 & $(0.00-117.11)$ & 0.00 & $(0.00-310.28)$ \\
\hline Pancreas & 1.01 & $(0.46-1.92)$ & 1.95 & $(0.78-4.02)$ & 1.95 & $(0.53-4.98)$ & 0.00 & $(0.00-3.49)$ & 0.00 & $(0.00-15.72)$ & 0.00 & $(0.00-42.09)$ \\
\hline Non-Hodgkin lymphoma & 1.04 & $(0.42-2.15)$ & 1.06 & $(0.22-3.09)$ & 0.00 & $(0.00-2.27)$ & 0.00 & $(0.00-3.61)$ & 0.00 & $(0.00-20.58)$ & 19.38 & $(0.49-108.01)$ \\
\hline Bile ducts, other biliary & 1.37 & $(0.75-2.31)$ & 0.72 & $(0.15-2.11)$ & 1.69 & $(0.46-4.34)$ & 3.45 & $(0.94-8.83)$ & 0.00 & $(0.00-13.89)$ & 9.79 & $(0.25-54.55)$ \\
\hline Stomach & 0.88 & $(0.62-1.22)$ & 1.14 & $(0.70-1.77)$ & 0.91 & $(0.42-1.73)$ & 0.36 & $(0.04-1.28)$ & 0.00 & $(0.00-3.44)$ & 0.00 & $(0.00-10.67)$ \\
\hline Liver & 0.84 & $(0.42-1.51)$ & 0.19 & $(0.00-1.08)$ & 0.00 & $(0.00-1.19)$ & 1.71 & $(0.35-5.00)$ & 0.00 & $(0.00-10.68)$ & 9.41 & $(0.24-52.43)$ \\
\hline Gallbladder & 0.38 & $(0.05-1.38)$ & 0.92 & $(0.11-3.33)$ & 1.63 & $(0.20-5.87)$ & 0.00 & $(0.00-6.08)$ & 0.00 & $(0.00-27.04)$ & 0.00 & $(0.00-71.35)$ \\
\hline Small intestine & 2.63 & $(0.54-7.69)$ & 2.17 & $(0.05-12.08)$ & 0.00 & $(0.00-13.56)$ & 0.00 & $(0.00-23.26)$ & 0.00 & $(0.00-123.21)$ & 0.00 & $(0.00-382.12)$ \\
\hline All excluding POFT & $1.26^{\#}$ & $(1.15-1.39)$ & $1.26^{\#}$ & $(1.09-1.45)$ & $1.64^{\#}$ & $(1.38-1.93)$ & 0.98 & $(0.74-1.27)$ & 1.31 & $(0.68-2.29)$ & $2.80^{\#}$ & $(1.13-5.77)$ \\
\hline
\end{tabular}

POFT: peritoneal, epithelial ovarian, and fallopian tubal; SIR: standardised incidence ratio; Cl: confidence interval

\#significant at $a=0.05$

cancer. In women with thyroid or breast cancer, the median overall survival was not reached and the 5 -year overall survival rates were good $(82.6$ and $70.5 \%$, respectively) compared to that in women with SPCs (56.0\%) and all women with POFT cancer irrespective of the development of an SPC (63.7\%). The median overall survival times were $2.9,1.6$, and 0.9 years in women with colorectal cancer, respiratory cancer, and hematopoietic malignancies, respectively.

\section{Discussion}

In the current study, the overall SIR for an SPC in survivors after POFT was 1.29 (95\% CI, 1.21-1.38) compared to the risk of SPCs in the general population. The risk of SPC increased in young women (SIR, 1.47) and after 10 years follow-up after the initial diagnosis of POFT cancers (SIR, 1.33-1.38). Shared aetiology of the POFT cancer and SPC could be identified in the current study, with ascending colon cancer (1.77), transverse colon cancer (2.43), and breast cancer (SIR, 1.26) being common SPCs. Leukaemia as an SPC, likely resulting from sequelae of active treatment for POFT, was also increased (3.07).
The 5-year overall survival rates were $88.8,74.4$, and $44.2 \%$ among patients with localized, regional, and distant stage disease, respectively. These rates are comparable to those observed among patients in the United States (92.6, 72.9 , and $28.0 \%$, respectively) [6].

POFT cancers are well established hereditary cancers based on mutations in BRCA1, BRCA2, and mismatch repair genes [7-9]. The life-time penetration of ovarian cancer is quite different depending on the type of genes involved. Recently, the cluster regions within $B R C A 1$ and $B R C A 2$ associated with specific cancers have been well established [10]. This means that the life-time risk of specific cancers can be discussed with patients based on their age, familial history, tumour location, type of gene, and specific cluster regions. Even though genetic information was not available in this study, the risk of SPCs after POFT cancer based on the hereditary background could be estimated and investigated. The risk of breast cancer increased 1.26 times, and in young women (aged < 60 years), the risk was 1.3. Further, in women with POFT cancer who had serous histology, the risk of breast cancer as an SPC was 1.58 (Table 3). Serous histology is one of 
Table 4 Risk of second primary cancer after primary POFT cancer diagnosis according to stage*

\begin{tabular}{|c|c|c|c|c|c|c|}
\hline \multirow[t]{2}{*}{ Stage } & \multicolumn{2}{|c|}{$\underline{\text { Localized }}$} & \multicolumn{2}{|c|}{$\underline{\text { Regional }}$} & \multicolumn{2}{|c|}{ Distant } \\
\hline & $\mathrm{SIR}$ & $\mathrm{Cl}$ & SIR & $\mathrm{Cl}$ & SIR & $\mathrm{Cl}$ \\
\hline Leukaemia & 2.73 & $(0.33-9.87)$ & 1.96 & $(0.05-10.92)$ & $4.94^{\#}$ & $(1.60-11.53)$ \\
\hline Urinary bladder & 0.00 & $(0.00-8.53)$ & 0.00 & $(0.00-11.82)$ & 4.51 & $(0.93-13.18)$ \\
\hline Lung, bronchus & $3.46^{\#}$ & $(1.94-5.71)$ & 0.61 & $(0.07-2.22)$ & 0.88 & $(0.32-1.92)$ \\
\hline Rectum, rectosigmoid junction & 1.89 & $(0.69-4.11)$ & 0.85 & $(0.10-3.06)$ & $2.28^{\#}$ & $(1.14-4.08)$ \\
\hline Thyroid & $2.38^{\#}$ & $(1.79-3.10)$ & 1.32 & $(0.80-2.03)$ & 1.19 & $(0.82-1.67)$ \\
\hline Colon & $2.10^{\#}$ & $(1.20-3.41)$ & 1.58 & $(0.72-2.99)$ & 1.36 & $(0.78-2.21)$ \\
\hline Ascending colon & 2.87 & $(0.78-7.34)$ & 1.88 & $(0.23-6.79)$ & 0.45 & $(0.01-2.48)$ \\
\hline Transverse colon & 1.72 & $(0.04-9.56)$ & 0.00 & $(0.00-8.36)$ & 0.00 & $(0.00-3.98)$ \\
\hline Descending colon & 1.94 & $(0.53-4.97)$ & 1.94 & $(0.40-5.67)$ & 0.63 & $(0.08-2.29)$ \\
\hline Rectum & 1.88 & $(0.69-4.10)$ & 0.84 & $(0.10-3.05)$ & $2.27^{\#}$ & $(1.13-4.06)$ \\
\hline Other and unspecified & 2.52 & $(0.06-14.05)$ & 7.03 & $(0.85-25.38)$ & 3.34 & $(0.40-12.05)$ \\
\hline Female breast & 0.99 & $(0.53-1.69)$ & 1.56 & $(0.85-2.62)$ & 1.27 & $(0.79-1.94)$ \\
\hline Kidney parenchyma & 2.19 & $(0.27-7.92)$ & 0.00 & $(0.00-5.45)$ & 2.21 & $(0.46-6.45)$ \\
\hline Renal pelvis, other urinary & 0.00 & $(0.00-18.45)$ & 0.00 & $(0.00-24.4)$ & $9.17^{\#}$ & $(1.89-26.8)$ \\
\hline Pancreas & 2.66 & $(0.73-6.82)$ & 0.89 & $(0.02-4.95)$ & 0.00 & $(0.00-1.54)$ \\
\hline Non-Hodgkin lymphoma & 1.49 & $(0.18-5.39)$ & 0.00 & $(0.00-3.79)$ & 0.52 & $(0.01-2.87)$ \\
\hline Bile ducts, other biliary & 1.89 & $(0.39-5.52)$ & 0.00 & $(0.00-3.11)$ & $3.12^{\#}$ & $(1.35-6.14)$ \\
\hline Stomach & 0.29 & $(0.04-1.05)$ & 0.99 & $(0.32-2.31)$ & 0.48 & $(0.16-1.12)$ \\
\hline Liver & 1.02 & $(0.12-3.69)$ & 0.66 & $(0.02-3.69)$ & 0.63 & $(0.08-2.29)$ \\
\hline Gallbladder & 1.24 & $(0.03-6.93)$ & 1.68 & $(0.04-9.39)$ & 0.00 & $(0.00-2.90)$ \\
\hline Small intestine & 0.00 & $(0.00-18.16)$ & 6.62 & $(0.17-36.87)$ & 0.00 & $(0.00-11.87)$ \\
\hline All excluding POFT & $1.72^{\#}$ & $(1.44-2.05)$ & 1.16 & $(0.89-1.50)$ & $1.28^{\#}$ & $(1.07-1.52)$ \\
\hline
\end{tabular}

*Stage data was used since 2006

POFT: peritoneal, epithelial ovarian, and fallopian tubal; SIR: standardised incidence ratio; Cl: confidence interval

\#significant at $\mathrm{a}=0.05$

the clinical markers suggesting hereditary predisposition for ovarian cancer [11]. The hereditary predisposed sites of colon cancer risk also increased, including ascending colon (2.26) and transverse colon (4.07) cancers, in POFT cancer survivors aged $<60$ years. The increased risk of breast cancer remained for 10 years after the diagnosis of POFT cancer (Table 2). Regarding colon cancer, the risk increased within 5 and 10 years after the diagnosis of POFT cancer. One of the reasons for the increased incidence of colon cancer at 5-10 years after the diagnosis of POFT cancer is that as a baseline work-up of POFT cancer, colonoscopy should be done according to the national insurance guidelines. This results in colon cancer and high-risk colonic polyps frequently being diagnosed together with POFT cancer, and such patients are enrolled in a continuous active surveillance program. Therefore, an individualised surveillance program for these two cancers, namely breast and colon cancers, could be suggested for survivors with POFT cancer, especially in the era of next-generation sequencing [12].

From the National Cancer Institute's Surveillance, Epidemiology and End Results database, the overall incidence of therapy-related acute myeloid leukaemia is $0.17 \%(109 / 63,359)$ [13]. The median survival time from the diagnosis is 3 months. In the current study, the risk of leukaemia as an SPC was higher among patients receiving chemotherapy than among those who did not receive chemotherapy. Age $>65$ years and development of secondary leukaemia are poor prognostic factors. In the current study, the risk of leukaemia increased in women aged $<60$ years (3.86) and during 10 years after the initial diagnosis of POFT cancer (3.16 until 5 years and 3.68 during 6-10 years after the initial diagnosis). After 10 years, the risk of leukaemia did not increase significantly. Serous histology (4.77) and distant stage (4.94) were additional risk factors for leukaemia, as leukaemia as an SPC relates to heavy treatment. The median overall survival time was 0.9 months, and more than half of the POFT cancer women with leukaemia (54.5\%) as an SPC died. In a previous study in a Taiwanese population, different chemotherapies were compared and 5-fluorouracil was suggested as an independent risk factor for SPC in the multivariate analysis [14]. In the current study, information on the specific chemotherapy regimen was not available to be 


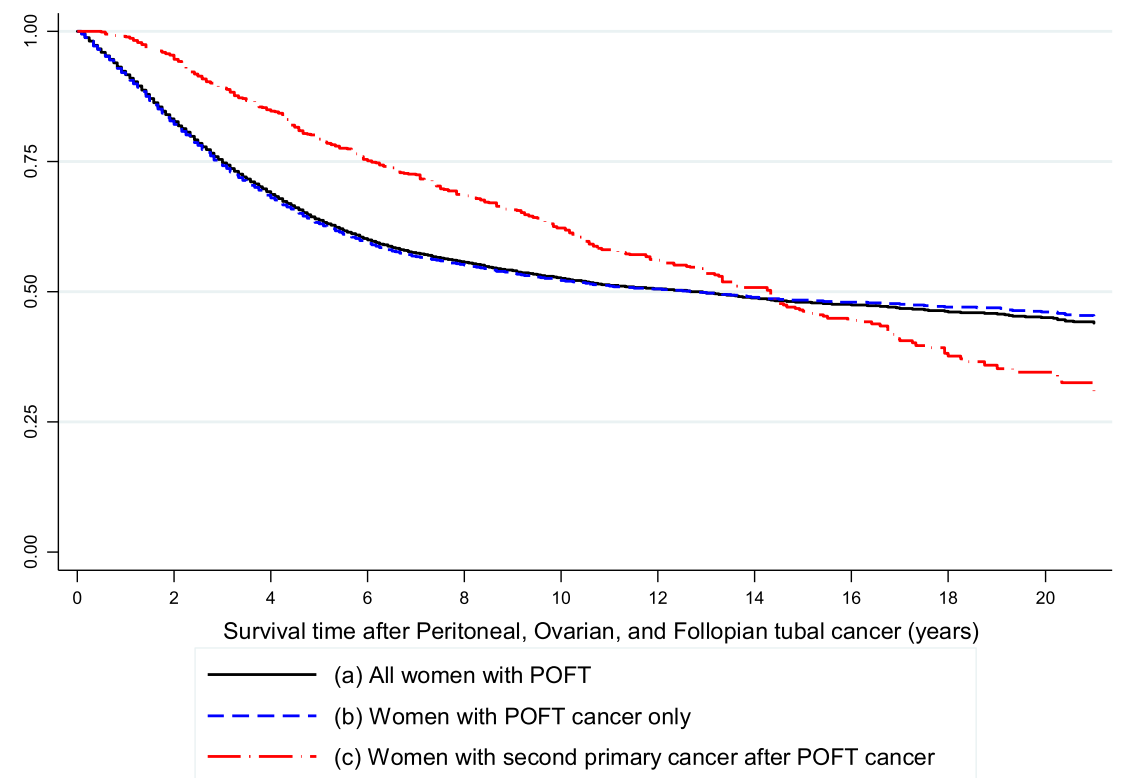

\begin{tabular}{|c|c|c|c|}
\hline & $\begin{array}{c}\text { All } \\
(\mathrm{n}=20738)\end{array}$ & $\begin{array}{c}\text { Only one cancer } \\
(\mathrm{n}=19940)\end{array}$ & $\begin{array}{c}\text { Second cancer } \\
(\mathrm{n}=798)\end{array}$ \\
\hline Median survival time (years) & 12.8 & 12.8 & 14.3 \\
\hline Survival probability (\%) & & & 91.4 \\
\hline 1 year & 91.7 & 82.1 & 94.7 \\
\hline 2 years & 82.6 & 74.2 & 89.1 \\
\hline 3 years & 74.8 & 68.1 & 84.7 \\
\hline 4 years & 68.8 & 63.0 & 79.4 \\
\hline 5 years & 63.7 & 56.8 & 72.5 \\
\hline 7 years & 57.4 & 52.2 & 62.3 \\
\hline 10 years & 52.5 & 48.4 & 46.2 \\
\hline 15 years & 48.0 & 46.2 & 34.5 \\
\hline 20 years & 45.0 & & \\
\hline
\end{tabular}

Log-rank $\mathrm{p}=0.0003<\alpha=0.05$

Fig. 1 Survival outcomes from the onset of peritoneal, ovarian, and fallopian tubal cancer. All women with peritoneal, ovarian, and fallopian tubal cancer (a); women with only peritoneal, ovarian, and fallopian tubal cancer (b); women with peritoneal, ovarian, and fallopian tubal cancer and with any second primary cancer (c)

analysed, whereas young age, serous histology, and distant stage, which are clinical factors requiring heavy treatment, were identified as risk factors for the development of leukaemia as an SPC after POFT cancer up to 10 years after the initial diagnosis of POFT cancer.

It is an interesting finding that the survival outcome in POFT cancer women with SPCs was better until nearly 14 years after the diagnosis of POFT cancer compared to in women without an SPC (Fig. 1-1). In particular, in POFT cancer women with thyroid and breast cancers as the SPC, the survival outcomes were particularly good compared to those with colorectal cancer, respiratory cancer, and hematopoietic malignancies. The higher number of patients in the subgroups showing good survival outcomes may be the reason for the improved survival outcomes in POFT cancer women with SPCs. Moreover, POFT cancer women with breast cancer as the SPC might have a higher possibility of BRCA1 or $B R C A 2$ germline mutation compared to women without breast cancer. In women with a pathogenic germline mutation in BRCA1 or BRCA2, the risks of death after adjustment for clinical variables including age, stage, 




\begin{tabular}{|c|c|c|c|c|c|c|}
\hline & $\begin{array}{c}\text { SPC } \\
(\mathrm{n}=798)\end{array}$ & $\begin{array}{c}\text { Thyroid } \\
(\mathrm{n}=200)\end{array}$ & $\begin{array}{c}\text { Breast } \\
(\mathrm{n}=116)\end{array}$ & $\begin{array}{c}\text { Colon, } \\
\text { rectum } \\
(\mathrm{n}=115)\end{array}$ & $\begin{array}{c}\text { Respiratory } \\
\text { system } \\
(\mathrm{n}=80)\end{array}$ & $\begin{array}{c}\text { Lymphatic- } \\
\text { hematopoietic } \\
(\mathrm{n}=36)\end{array}$ \\
\hline Median survival time (years) & 6.9 & - & - & 2.9 & 1.6 & 0.9 \\
\hline Survival probability (\%) & & & & & & \\
\hline 1 & 80.5 & 96.0 & 93.9 & 75.0 & 66.2 & 45.5 \\
\hline 2 & 69.8 & 92.7 & 85.7 & 57.8 & 44.4 & 32.6 \\
\hline 3 & 63.0 & 88.2 & 81.5 & 48.8 & 42.9 & 29.4 \\
\hline 4 & 58.1 & 83.7 & 73.3 & 41.5 & 38.9 & 29.4 \\
\hline 5 & 56.0 & 82.6 & 70.5 & 40.1 & 34.4 & 29.4 \\
\hline 7 & 49.3 & 80.0 & 62.3 & 30.5 & 23.8 & 22.0 \\
\hline 10 & 43.7 & 70.0 & 59.6 & 26.1 & 20.9 & 22.0 \\
\hline 15 & 38.5 & 70.0 & 59.6 & - & 10.4 & - \\
\hline 20 & - & - & - & - & - & - \\
\hline
\end{tabular}

Log-rank $\mathrm{p}=0.0001<\alpha=0.05$

Fig. 2 Survival outcomes in peritoneal, ovarian, and fallopian tubal cancer patients with a second primary cancer. Survival time from the onset of any second primary cancer $(\mathbf{a})$, thyroid $(\mathbf{b})$, breast $(\mathbf{c})$, colon $(\mathbf{d})$, respiratory system $(\mathbf{e})$, and lymphatic-hematopoietic $(\mathbf{f})$ second primary cancers

grade, and histology, were decreased, with hazard ratios of 0.73 for BRCA1 and 0.49 for BRCA2 [15]. Although the incidence of thyroid cancer in Korean women is the 2nd highest of all cancers, the risk of mortality is not high compared to that in the general population, with an age-standardised mortality rate of $0.3 / 100,000$ [3]. Subgroups of cancers with good biomarkers and effective targeted therapy or immunotherapy based on hereditary factors could reveal improvements of the survival outcomes in the near future [16].

One of the merits in this study is that all cancers were covered by the national cancer centre registry, and all POFT cancers and SPCs were systemically registered by well-trained medical record administrators who were regularly educated. This means minimisation of selection bias and good reproducibility of this study. However, the applicability of these data to non-Korean populations may be limited. To our knowledge, this is the first study to evaluate the development and types of SPC after POFT cancer, not only ovarian cancer. POFT cancers are more homogenous and reproducible in terms of genetic background and clinical scenarios. On the other hand, one of the limitations in this study is that we used limited clinical variables. Thus, the impact of several clinical variables on the development of SPC could not be evaluated, which could be potentially important in daily clinical practice.

\section{Conclusions}

In conclusion, the risk of SPC is increased in POFT survivors up to 10 years after the diagnosis of POFT and in young survivors ( $<60$ years). Proximal colon and breast cancers, especially in young POFT cancer survivors, are 
SPCs suggesting hereditary predisposition. Leukaemia tended to develop in women who were heavily treated, especially in cases of young age, serous histology, and distant stage, suggesting that this SPC is chemotherapy-related. Nevertheless, the survival outcome in POFT cancer women with an SPC was favourable. In particular, the development of thyroid and breast cancers as SPCs in women with POFT cancer suggests favourable prognoses. The results of the present study can be used for the surveillance of POFT cancer survivors and to estimate the prognoses of women with POFT cancer and SPCs.

\section{Additional file}

Additional file 1: Figure S1. Survival outcomes from onset of POFT

cancer according to stage. (TIF $67 \mathrm{~kb}$ )

\section{Abbreviations \\ Cl: Confidence interval; POFT: Peritoneal, epithelial ovarian, and fallopian tubal; PYR: Person-year at risk; SIR: Standardised incidence ratio; SPC: Second primary cancer}

\section{Funding}

This study was supported by a National Cancer Center Grant (NCC-1610200). The funding source has not any involvement in the study design, in the collection, analysis and interpretation of data, in the writing of the report and in the decision to submit the paper for publication.

\section{Availability of data and materials}

The data that support the findings of this study are available from the KCCR but restrictions apply to the availability of these data, which were used under license for the current study, and so are not publicly available. Data are however available from the authors upon reasonable request and with permission of the KCCR

\section{Authors' contributions}

MCL and YJW conceived the study, participated in its design, wrote the paper and provided final approval of the manuscript. $J \mathrm{~L}$ analysed the data and reviewed the literature. TS, CWY and REB provided critical comments and suggestions for the important intellectual content of this study. All authors read and approved the final manuscript.

\section{Ethics approval and consent to participate}

This study was reviewed and approved by the Ethics committee of National Cancer Center on 14 July 2017. The approval number is No. NCC2017-0167. We requested and obtained the cancer registration data (de-identified) used in this study from the Korea Central Cancer Registry (KCCR).

\section{Consent for publication}

Not applicable.

\section{Competing interests}

The authors declare that they have no competing interests.

\section{Publisher's Note}

Springer Nature remains neutral with regard to jurisdictional claims in published maps and institutional affiliations.

\section{Author details}

${ }^{1}$ Division of Gynecologic Oncology, Obstetrics and Gynecology, Irvine Medical Center, University of California, California, USA. ${ }^{2}$ Center for Uterine Cancer and Center for Clinical Trials, Hospital, National Cancer Center, Goyang, Republic of Korea. ${ }^{3}$ Cancer Healthcare Research Branch, Research Institute, National Cancer Center, Goyang, Republic of Korea. ${ }^{4}$ Department of Cancer Control \& Population Health, Graduate School of Cancer Science and
Policy, National Cancer Center, Goyang, Republic of Korea. ${ }^{5}$ Cancer Registration and Statistics Branch, National Cancer Control Institute, National Cancer Center, Goyang, Republic of Korea.

Received: 2 April 2018 Accepted: 27 July 2018

Published online: 08 August 2018

\section{References}

1. Siegel RL, Miller KD, Jemal A. Cancer statistics, 2017. CA Cancer J Clin. 2017; 67(1):7-30.

2. Lim MC, Moon E-K, Shin A, Jung K-W, Won Y-J, Seo SS, Kang S, Kim J-W, Kim $J-Y$, Park S-Y. Incidence of cervical, endometrial, and ovarian cancer in Korea, 1999-2010. J Gynecol Oncol. 2013;24(4):298-302.

3. Jung KW, Won YJ, Oh CM, Kong HJ, Lee DH, Lee KH. Prediction of Cancer incidence and mortality in Korea, 2017. Cancer Res Treat. 2017:49(2):306-12.

4. Berek JS, Crum C, Friedlander M. Cancer of the ovary, fallopian tube, and peritoneum. Int J Gynaecol Obstet. 2015;131(Suppl 2):S111-22.

5. Bae HS, Lim MC, Lee JS, Lee Y, Nam BH, Seo SS, Kang S, Chung SH, Kim JY, Park SY. Postoperative lower extremity edema in patients with primary endometrial Cancer. Ann Surg Oncol. 2016;23(1):186-95.

6. SEER*Explorer: An interactive website for SEER cancer statistics [Internet] Surveillance Research Program, National Cancer Institute. [cited June 17 2018]. Available from [https://seer.cancer.gov/explorer/].

7. Lim MC, Kang S, Seo SS, Kong SY, Lee BY, Lee SK, Park SY. BRCA1 and BRCA2 germline mutations in Korean ovarian cancer patients. J Cancer Res Clin Oncol. 2009:135(11):1593-9.

8. Russo A, Calo V, Bruno L, Rizzo S, Bazan V, Di Fede G. Hereditary ovarian cancer. Crit Rev Oncol Hematol. 2009;69(1):28-44.

9. Lim MC, Seo SS, Kang S, Seong MW, Lee BY, Park SY. Hereditary nonpolyposis colorectal cancer/lynch syndrome in Korean patients with endometrial cancer. Jpn J Clin Oncol. 2010;40(12):1121-7.

10. Rebbeck TR, Mitra N, Wan F, Sinilnikova OM, Healey S, McGuffog L, Mazoyer S, Chenevix-Trench G, Easton DF, Antoniou AC, et al. Association of type and location of BRCA1 and BRCA2 mutations with risk of breast and ovarian cancer. JAMA. 2015;313(13):1347-61.

11. Schrader KA, Hurlburt J, Kalloger SE, Hansford S, Young S, Huntsman DG, Gilks CB, McAlpine JN. Germline BRCA1 and BRCA2 mutations in ovarian cancer: utility of a histology-based referral strategy. Obstet Gynecol. 2012;120(2 Pt 1):235-40.

12. Lim MC, Randall LM. Role and clinical application of next-generation sequencing (NGS) for ovarian cancer. J Gynecol Oncol. 2017;28(4):e51.

13. Vay A, Kumar S, Seward S, Semaan A, Schiffer CA, Munkarah AR, Morris RT. Therapy-related myeloid leukemia after treatment for epithelial ovarian carcinoma: an epidemiological analysis. Gynecol Oncol. 2011;123(3):456-60.

14. Hung YP, Liu CJ, Hu YW, Chen MH, Li CP, Yeh CM, Chiou TJ, Chen TJ, Yang $\mathrm{MH}$, Chao $\mathrm{Y}$. Secondary primary malignancy risk in patients with ovarian Cancer in Taiwan: a Nationwide population-based study. Medicine (Baltimore). 2015;94(38):e1626.

15. Bolton KL, Chenevix-Trench G, Goh C, Sadetzki S, Ramus SJ, Karlan BY, Lambrechts D, Despierre E, Barrowdale D, McGuffog L, et al. Association between BRCA1 and BRCA2 mutations and survival in women with invasive epithelial ovarian cancer. JAMA. 2012;307(4):382-90.

16. Le DT, Uram JN, Wang H, Bartlett BR, Kemberling H, Eyring AD, Skora AD, Luber BS, Azad NS, Laheru D, et al. PD-1 blockade in tumors with mismatchrepair deficiency. N Engl J Med. 2015;372(26):2509-20.

Ready to submit your research? Choose BMC and benefit from:

- fast, convenient online submission

- thorough peer review by experienced researchers in your field

- rapid publication on acceptance

- support for research data, including large and complex data types

- gold Open Access which fosters wider collaboration and increased citations

- maximum visibility for your research: over $100 \mathrm{M}$ website views per year

At BMC, research is always in progress.

Learn more biomedcentral.com/submission 